\title{
Germ cell tumour as a diagnostic pitfall of metastatic carcinoma
}

\author{
T W H Shek, S T Yuen, I S C Luk, M P Wong
}

\begin{abstract}
Aim-Testicular germ cell tumours may present as metastases in cervical lymph nodes, yet the primary tumours remain clinically occult. The aim of the study is to alert pathologists and clinicians to this uncommon but important presentation and highlight the clues and the diagnostic adjuncts to its correct diagnosis.

Methods-The clinical, cytological, histological, and immunohistochemical features of two patients with germ cell tumour initially presenting as cervical lymphadenopathy were described and analysed. Results-Both patients were young adult males, who were found to have metastatic undifferentiated carcinoma on fine needle aspiration of the enlarged cervical lymph nodes. The tumour cells in both cases were positive for placental alkaline phosphatase (PLAP) and negative for epithelial membrane antigen (EMA).

Conclusions-Clinicians and pathologists should be aware of the possibility of germ cell tumour when encountering a young adult male with metastatic poorly differentiated carcinoma. Positivity for PLAP and negativity for EMA are helpful adjuncts in arriving at the correct diagnosis. (f Clin Pathol 1996;49:223-225)
\end{abstract}

Keywords: germ cell tumour, carcinoma of unknown primary, cytology, placental-like alkaline phosphatase.

Fine needle aspiration cytology (FNAC) of cervical lymphadenopathy is a simple, safe, and relatively cheap diagnostic procedure. The diagnostic accuracy of FNAC for metastatic carcinomas in lymph node is around $90-95 \% .^{12}$ The cytological appearances of metastatic neoplasms in lymph nodes are in general similar to their primary tumours, which have been described in detail in standard textbooks. ${ }^{34}$ The presence of clusters of undifferentiated carcinoma cells on FNAC smears of a patient with cervical lymphadenopathy generally signifies metastatic carcinoma, which prompts the clinician to investigate for possible primary tumours, usually in areas such as the upper aerodigestive tract and the head and neck region. In southern China, where the incidence of undifferentiated nasopharyngeal carcinoma is very high, presence of undifferentiated carcinoma cells in cervical lymph node aspirate is virtually diagnostic of metastatic nasopharyngeal carcinoma. Germ cell tumour, on the other hand, is relatively rare among Asians ${ }^{5}$ and therefore clinicians and pathologists in
Asian countries may not have considered metastatic germ cell tumour as one of the differential diagnoses in this clinical situation. The treatment for metastatic carcinoma is palliative and the prognosis is generally dismal. Such grave prognosis of metastatic carcinoma contrasts remarkably with that of the potentially curable germ cell tumour, even when disseminated. Therefore it is crucial for the pathologist to be able to recognise germ cell tumour and to alert the clinicians to such a possibility.

\section{Case report}

CASE 1

A 36 year old Caucasian man was incidentally found to have enlarged left supraclavicular and left cervical lymph nodes. Chest $x$ ray showed multiple cannon ball lesions in both lung fields. He was otherwise well with no specific complaints. FNAC was performed on the left cervical lymph nodes. Direct smears showed clusters of malignant tumour cells with centrally located nuclei and fairly abundant eosinophilic cytoplasm. A prominent central nucleolus was noted in many of the nuclei. Interspersed between these mononucleated tumour cells were occasional multinucleated giant cells (fig 1). Staining for mucin on the cell block preparation was negative; immunohistochemical staining for MAK-6 (Ciba) was positive but that for S-100 (Dako), epithelial membrane antigen (Dako), and leucocyte common antigen (Dako) was negative. The smears were interpreted as metastatic undifferentiated carcinoma; the primary site of the malignancy was unknown.

During the course of investigation, he was found to have retroperitoneal lymphadenopathy and the possibility of a testicular germ cell tumour was raised. Although no testicular mass was palpable, ultrasonography showed a tumour in the left testis, which was consistent with a germ cell tumour. Blood investigation showed raised human chorionic gonadotrophin (hCG), while $\alpha$ fetoprotein was within normal limits. Cisplatin based systemic chemotherapy was initiated to which he responded well.

Retrospective immunohistochemical studies on the cell block preparation showed that the mononucleated tumour cells were positive for PLAP (placental alkaline phosphatase) (Dako) and the multinucleated giant cells were positive for human chorionic gonadotrophin (Dako), in keeping with embryonal carcinoma with a minor component of syncytiotrophoblastic giant cells. No other germ cell components were identified. 


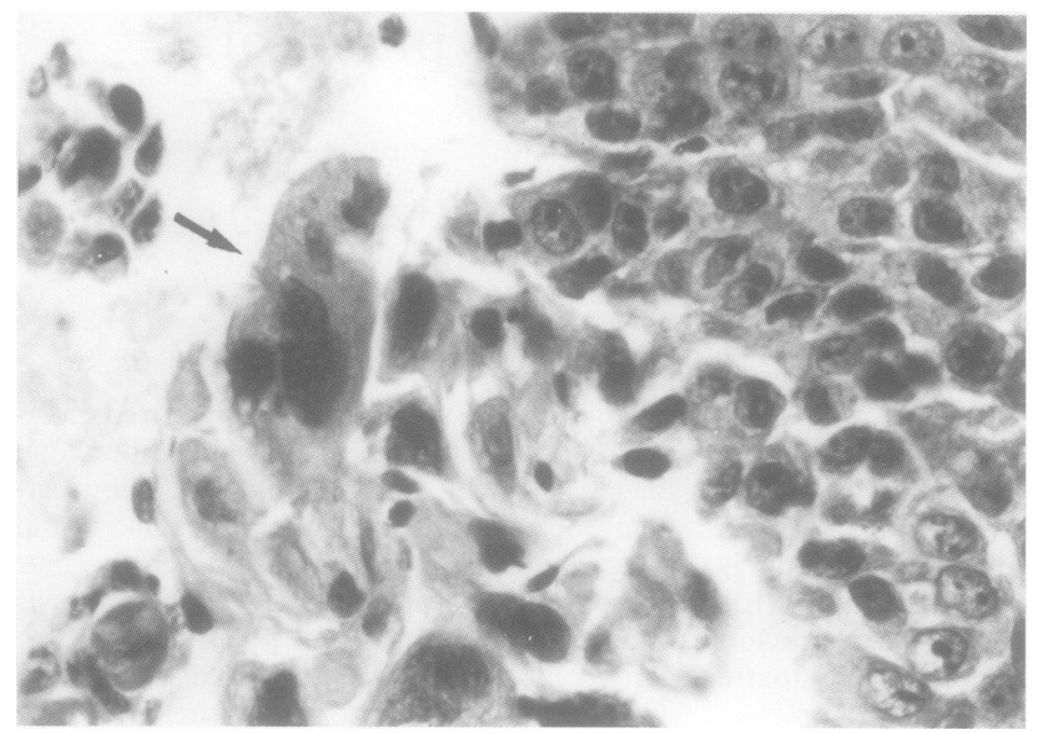

Figure 1 Clusters of undifferentiated malignant cells admixed with trophoblastic giant cells (arrow).

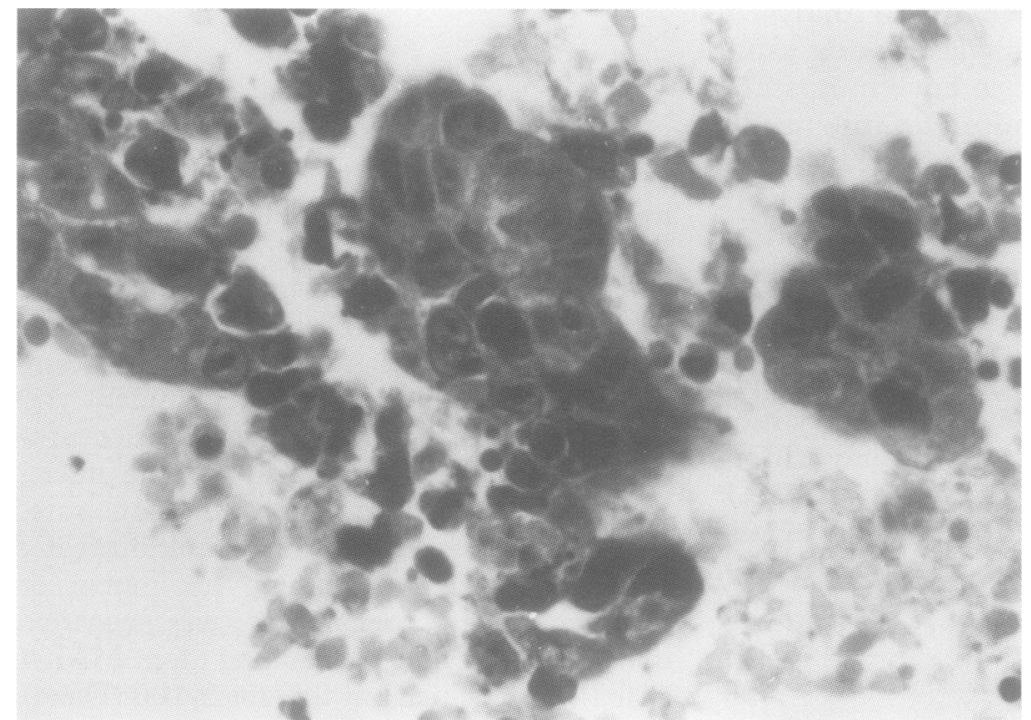

Figure 2 Small clusters of undifferentiated malignant cells with acinar arrangement.

CASE 2

A 23 year old Chinese man presented with two day history of low grade fever. Physical examination showed multiple enlarged left lower cervical lymph nodes. Chest $x$ ray showed clear lung fields but the mediastinum was slightly enlarged. The tuberculin skin test was positive, and the presumptive clinical diagnosis was tuberculous lymphadenopathy. FNAC was performed and all the aspirated material was fixed in $10 \%$ buffered formalin. The cell block preparation revealed dense clusters of malignant tumour cells with focal areas showing acinar arrangement. The nuclei were pleomorphic, centrally located, and had prominent nucleoli (fig 2). Staining for mucin was negative. Immunohistochemical stains for PLAP and MAK- 6 were positive, but those for $\alpha$ fetoprotein and hCG were negative. In view of these findings, the young age of the patient, and our experience with the previous case, the possibility of metastatic germ cell tumour, in particular embryonal carcinoma, was raised.
Subsequent physical examination showed a right testicular swelling. Computed axial tomography showed enlarged retroperitoneal and mediastinal lymph nodes, consistent with metastatic disease. No metastasis was detected in the lungs. Blood tests, however, showed normal serum concentrations of hCG and $\alpha$ fetoprotein. Right inguinal orchidectomy was performed and a $3 \times 2.5 \times 2.5 \mathrm{~cm}$ yellow tumour was found in the right testis. Histology showed a pure embryonal carcinoma with solid as well as glandular architectures identified (fig 3 ). The adjacent testis showed extensive intratubular germ cell neoplasia. Immunohistochemical study showed that the tumour cells expressed MAK-6, PLAP, and Ki-1 (Dako) but not $\alpha$ fetoprotein, hCG, epithelial membrane antigen, or leucocyte common antigen. Cisplatin based systemic chemotherapy was given, to which he responded well.

\section{Discussion}

Germ cell tumours constitute more than $95 \%$ of primary neoplasms of the testis and they show a predilection for young adults. ${ }^{5}$ They can be broadly divided into seminoma and nonseminomatous germ cell tumours (NSGCT). The majority of germ cell tumour present as painless testicular enlargement, but around 10$20 \%$ of testicular germ cell tumours, especially NSGCT, may present initially as metastatic disease. ${ }^{6}$ There has been remarkable advance in the treatment of germ cell tumour in the past two decades and most patients with these tumours, even those with disseminated disease, are expected to respond to modern chemotherapy and are potentially curable. There is a significant geographic heterogeneity in the incidence of germ cell tumour and it is relatively uncommon among orientals. For example, whites in North America and Scandinavia have an incidence up to eight times that of native Japanese. ${ }^{5}$ Asian pathologists may therefore be less familiar with this diagnosis. However, as germ cell tumours affect young adults and are potentially curable by modern chemotherapy, a missed diagnosis has serious implications.

The role of FNAC is well established for the clinical staging of germ cell tumour, ${ }^{9}$ and the cytological appearance has been reviewed previously. ${ }^{348}$ The cytological features of seminoma are fairly characteristic, comprising a homogeneous population of malignant cells which are regular and large, with central round nuclei, each containing a prominent nucleolus. The chromatin is fine and evenly distributed and the cytoplasm appears vacuolated, due to glycogen. The cytological features of embryonal carcinoma are less specific and are indistinguishable from other poorly differentiated malignancies ${ }^{7}$ such as carcinoma, melanoma, and lymphoma, especially anaplastic large cell lymphoma. The cytological differentiation of this group of neoplasms can be very subtle and other auxiliary diagnostic techniques are usually required for the definitive diagnosis.

A very high index of suspicion is therefore required for the diagnosis of metastatic germ 


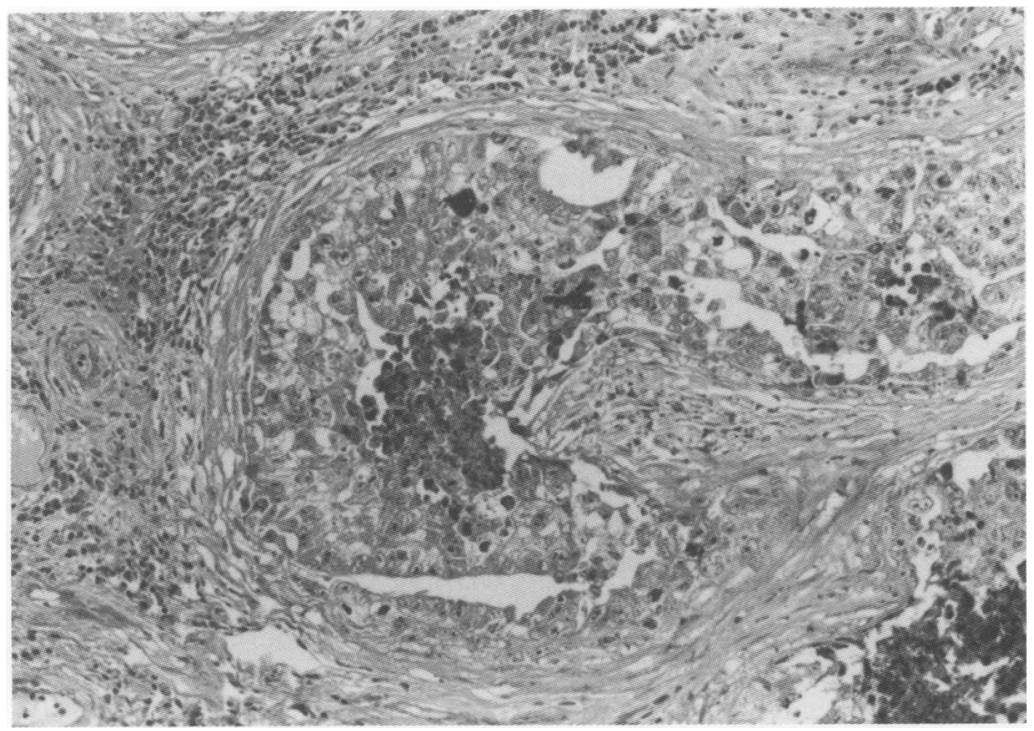

Figure 3 Irregular nests of embryonal carcinoma with central necrosis.

cell tumour, especially pure embryonal carcinoma. Unless the pathologist is aware of this possibility, the FNAC smears can be easily misinterpreted as metastatic undifferentiated carcinoma and the patient deprived of the potentially curable chemotherapy. The presence of multinucleated syncytiotrophoblastic giant cells is a very characteristic feature of choriocarcinoma, but they can also be seen in seminoma, as well as in mixed germ cell tumour. However, these giant cells are not pathognomonic of germ cell tumours and they have been described occasionally in ordinary carcinomas of the gastrointestinal tract, ${ }^{910}$ urinary bladder, ${ }^{11}$ ureter, ${ }^{12}$ endometrium, ${ }^{13}$ and ovary. ${ }^{14}$ The young age of the patient is a very important clue for the diagnosis. Germ cell tumour occurs in young adults, while metastatic carcinoma tends to affect elderly subjects.

Immunohistochemical study plays an important role in the diagnosis of metastatic germ cell tumours. PLAP is highly sensitive for these tumours, with over $95 \%$ positivity. ${ }^{1516}$ Our findings confirm the previous observation that epithelial membrane antigen is of discriminating value in distinguishing germ cell tumours and carcinomas, being uniformly negative in the former and nearly uniformly positive in the latter. ${ }^{16} \mathrm{Ki}-1$ positivity in embryonal carcinoma can be a diagnostic pitfall for anaplastic large cell lymphoma. ${ }^{17}$ However, the latter also expresses leucocyte common antigen and epithelial membrane antigen.

Recently, it has been proposed that a proportion of disseminated carcinomas with unknown primary are related to an occult germ cell tumour. ${ }^{1819}$ The good response of a number of such cases to a cisplatin based chemotherapeutic regimen is consistent with this hypothesis. ${ }^{19}$ Recent developments in DNA analysis and chromosomal studies may prove useful in distinguishing between disseminated germ cell tumour and carcinoma. The characteristic isochromosome $12 \mathrm{p}^{2021}$ and the consistent aneuploid DNA content ${ }^{2223}$ in testicular germ cell tumours are potentially useful additional diagnostic tools. Such techniques are readily applicable to FNAC material.

1 Kline TS, Kannan V, Kline IK. Lymphadenopathy and aspiration biopsy cytology: Review of 376 superficial nodes. Cancer 1984;54:1076-81

2 Lee RE, Valaitis J, Kalis O, Sophian A, Schultz E. Lymph node examination by fine needle aspiration in patients with known or suspected malignancy. Acta Cytol 1987;31: 563-72.

3 Das DK. Cytopathology of the lymph node. In: Bibbo M, ed. Comprehensive cytopathology. Philadelphia: W B Saunders Co, 1991:671-702.

4 Suen KC. Atlas of aspiration biopsy cytology. Baltimore: Williams and Wilkins, 1990.

5 True LD, Rosai J. Tumours of the testis. In: McGee JO'G, Isaacson PG, Wright NA, eds. Oxford textbook of pathology. Oxford: Oxford University Press, 1992:1554-62.

6 Mostofi FK, Price EB. Tumors of the male genital system. Fascicle 8. Atlas of tumour pathology, 2nd series. Washington, DC: Armed Forces Institute of Pathology, 1973.

7 Highman WJ, Oliver RT. Diagnosis of metastatic testicular germ cell tumors using fine needle aspiration cytology. $\mathcal{F}$ Clin Pathol 1987;40:1324-33.

8 Fleury-Feith J, Bellot-Besnard J. Criteria for aspiration cytology for the diagnosis of seminoma. Diagn Cytopathol 1989; 5:392-5.

9 Kubosawa H, Nagoa K, Kondo Y. Coexistence of adenocarcinoma and choriocarcinoma in the sigmoid colon. Cancer 1948;54:866-8.

10 Yakeishi Y, Mori M, Enjoji M. Distribution of $\beta$-human chorionic gonadotrophin-positive cells in noncancerous gastric mucosa and in malignant gastric tumors. Cancer 1990;66:695-701.

11 Young RH, Eble JN. Unusual forms of carcinoma of the urinary bladder. Hum Pathol 1991;22:948-65.

12 Oyasu R, Nan L, Smith DP, Kawamata H. Human chorionic gonadotropin beta-subunit synthesis by undifferentiated urothelial carcinoma with syncytiotrophoblastic differurothelial carcinoma with syncytiotrophoblastic

13 Pesce C, Merino MJ, Chambers JT, Nogales F. Endometrial carcinomas with trophoblastic differentiation. An aggressive form of uterine cancer. Cancer 1991;68:1799-802.

14 Oliva E, Andrada E, Pezzica E, Prat J. Ovarian carcinomas with choriocarcinomatous differentiation. Cancer 1993; 72:2441-6.

15 Burke AP, Mostofi FK. Placental alkaline phosphatase immunohistochemistry of intratubular malignant germ cells and associated testicular germ cell tumors. Hum Pathol 1988;19:663-70.

16 Wick MR, Swanson PE, Manivel JC. Placental-like alkaline phosphatase reactivity in human tumors. Hum Pathol phosphatase reactiv

17 Pallesen G, Hamilton-Dutoit SJ. Ki-1 (CD30) antigen is regularly expressed by tumour cells of embryonal carcinoma. Am ₹ Pathol 1988;133:446-50.

18 Hainsworth JD, Greco FA. Poorly differentiated carcinoma and germ cell tumors. Hematol Oncol Clin North Am 1991; 5:1223-31.

19 Sporn JR, Greenberg BR. Empiric chemotherapy in patients with carcinoma of unknown primary site. Am $\mathcal{F}$ Med 1990; 88:49-55.

20 Atkin NB, Baker MC. i(12p): specific chromosomal marker in seminoma and malignant teratoma of the testis? Cancer in seminoma and malignant terato

21 Castedo SMMJ, de Jong B, Oosterhuis JW, Seruca R, vte Meerman G, Dam A, et al. Cytogenetic analysis of ten human seminomas. Cancer Res 1989;49:439-43.

22 El-Naggar AK, Ro JY, McLemore D, Ayala AG, Batsakis JG. DNA ploidy in testicular germ cell neoplasms. $A m \mathcal{F}$ Surg Pathol 1992;16:616-8.

23 Oosterhius JW, Castedo SMMJ, de Jong B, Cornelisse CJ, Dam A, Sleijfer DT, et al. Ploidy of primary germ cell tumors of the testis. Pathogenetic and clinical relevance. Lab Invest 1989;60:14-21 